\title{
Characterisation of Zinc Oxide and Cadmium Oxide Nanostructures Obtained from the Low Temperature Thermal Decomposition of Inorganic Precursors
}

\author{
K. Kalpanadevi, C. R. Sinduja, and R. Manimekalai \\ Department of Chemistry, Kongunadu Arts and Science College, Coimbatore, Tamil Nadu 641 029, India \\ Correspondence should be addressed to R. Manimekalai; manimekalair@ymail.com
}

Received 16 June 2013; Accepted 5 August 2013

Academic Editors: A. Abu-Surrah, K. Y. Choi, and A. Lehtonen

Copyright (C) 2013 K. Kalpanadevi et al. This is an open access article distributed under the Creative Commons Attribution License, which permits unrestricted use, distribution, and reproduction in any medium, provided the original work is properly cited.

Low temperature syntheses of zinc oxide and cadmium oxide nanoparticles are reported in this paper. The inorganic precursor complexes were prepared and characterised by hydrazine and metal analyses, infrared spectral analysis, and thermal analysis. Using appropriate annealing conditions, zinc oxide and cadmium oxide nanoparticles of average particle sizes around $13 \mathrm{~nm}$ and $30 \mathrm{~nm}$ were synthesised from the precursors by a simple thermal decomposition route. The synthesised nanoparticles were characterised for their size and structure using X-Ray diffraction (XRD), high resolution transmission electron microscopy (HRTEM), selected area electron diffraction (SAED), and scanning electron microscopy (SEM) techniques.

\section{Introduction}

This century has witnessed a tremendous escalation in the field of science and technology, for which the contribution of nanotechnology is much substantial. In the past decade, nanoscale research has opened revolutionary opportunities for a wide number of technological applications. Due to their special optical, magnetic, electrical, and catalytic properties and improved physical properties like mechanical hardness, thermal stability, or chemical passivity [1], metal oxide nanostructures are extensively used as paint pigments, cosmetics, pharmaceuticals, medical diagnostics, catalysts and supports, membranes and filters, batteries and fuel cells, electronics, magnetic and optical devices, flat panel displays, biomaterials, structured materials, and protective coatings [2].

Nanostructures based on zinc oxide and cadmium oxide are particularly interesting because of their n-type conductivity with a wide band gap ( $3.3 \mathrm{eV}$ and $2.2 \mathrm{eV}$, resp.) which makes these materials more suitable for modern technologies. $\mathrm{ZnO}$ and $\mathrm{CdO}$ have promising applications in catalysts $[3,4]$, gas sensors $[5,6]$, solar cells $[7,8]$, paint pigments, and so on.

There are several accepted techniques for the preparation of $\mathrm{ZnO}$ and $\mathrm{CdO}$ nanoparticles such as sol-gel method
$[9,10]$, microemulsion method $[11,12]$, precipitation method, thermal decomposition [13], hydrothermal method [14, 15], chemical coprecipitation method [16], and thermal evaporation [17]. One of the simplest methods to obtain $\mathrm{ZnO}$ and $\mathrm{CdO}$ nanoparticles is the thermal decomposition of a suitable precursor. In this context, we have attempted to synthesise $\mathrm{ZnO}$ and $\mathrm{CdO}$ nanoparticles by the thermal decomposition route from the corresponding inorganic precursor $\mathrm{M}(\mathrm{cin})_{2} \cdot\left(\mathrm{N}_{2} \mathrm{H}_{4}\right)_{2}(\mathrm{M}=\mathrm{Zn} / \mathrm{Cd}$, cin = cinnamic acid $)$ which involves low temperature, low cost, and low time consumption.

\section{Experimental}

2.1. Preparation of the Precursor $M(\operatorname{cin})_{2} \cdot\left(\mathrm{N}_{2} \mathrm{H}_{4}\right)_{2}(\mathrm{M}=\mathrm{Zn} / \mathrm{Cd}$, cin = Cinnamic Acid). The precursor complex was prepared by the addition of an aqueous solution $(50 \mathrm{~mL})$ of hydrazine hydrate $(1 \mathrm{~mL}, 0.01 \mathrm{~mol})$ and cinnamic acid $(0.74 \mathrm{~g}$ and $0.055 \mathrm{~mol})$ to the corresponding aqueous solution $(50 \mathrm{~mL})$ of metal nitrate hexahydrate $(0.7437 \mathrm{~g}$ and $0.002 \mathrm{~mol}$ of zinc nitrate hexahydrate and $0.77 \mathrm{~g}, 0.002 \mathrm{~mol}$ of cadmium nitrate hexahydrate). The complex formed immediately was kept aside for an hour for digestion, then filtered and washed with water and alcohol followed by diethylether, and air-dried. 


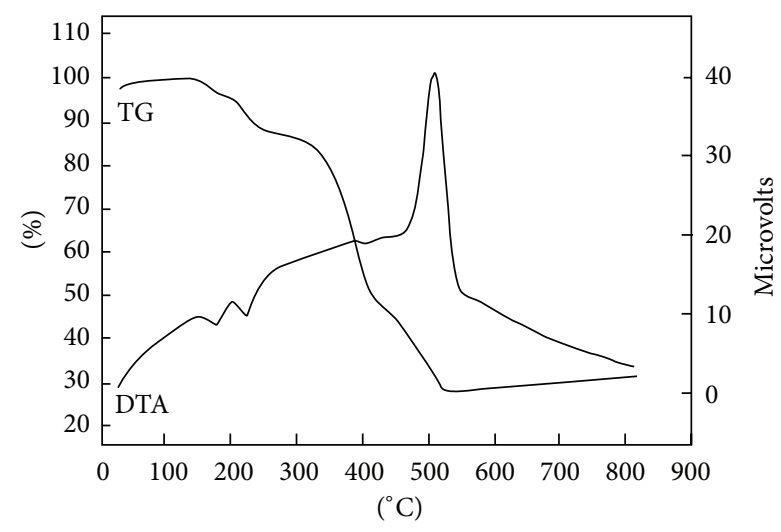

(a)

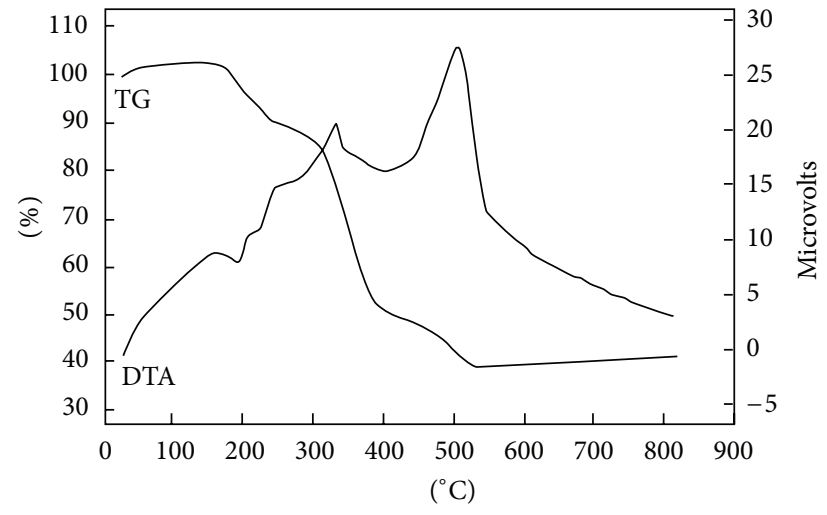

(b)

FIgURE 1: (a) TG-DTA curve of $\mathrm{Z}(\operatorname{cin})_{2} \cdot\left(\mathrm{N}_{2} \mathrm{H}_{4}\right)_{2}$, (b) TG-DTA curve of Cd( $\left.\operatorname{cin}\right)_{2} \cdot\left(\mathrm{N}_{2} \mathrm{H}_{4}\right)_{2}$.

2.2. Preparation of Metal Oxide Nanoparticles. Zinc oxide and cadmium oxide nanoparticles were obtained from the autocatalytic decomposition of their respective precursors.In this method,the dried precursor was transferred to a silica crucible and heated to red hot condition in an ordinary atmosphere for about 45 minutes.The precursor started decomposing violently.The total decomposition of the precursor complex led to the formation of the corresponding oxide nanoparticles, which are quenched to room temperature, ground well, and stored.

2.3. Quantitative Methods. The hydrazine content in the precursor was determined by titration using $\mathrm{KIO}_{3}$ as the titrant [18]. The percentage of the metal (zinc or cadmium) in the precursor was estimated by the standard methods given in the Vogel's textbook [18] and that in the corresponding oxide was known from SEM-EDAX.

\subsection{Physicochemical Techniques}

2.4.1. Infrared Spectrum. The infrared spectrum of the solid precursor sample was recorded by the $\mathrm{KBr}$ disc technique using a Perkin Elmer 597/1650 spectrophotometer.

2.4.2. Thermal Analysis. The simultaneous TG-DTA experiment was carried out in Shimadzu DT40, Stanton 781, and STA 1500 thermal analyzers. Thermal analysis was carried out in air at the heating rate of $10^{\circ} \mathrm{C}$ per minute using 5-10 $\mathrm{mg}$ of the sample. Platinum cups were used as sample holders and alumina as reference. The temperature range was ambient to $700^{\circ} \mathrm{C}$.

\subsection{Characterization of Nanoparticles}

2.5.1. HRTEM. The particle size of the synthesised nanoparticles was determined by high resolution transmission electron microscopy (HRTEM) operating on Hitachi Model H-800 using an accelerating voltage of $200 \mathrm{kV}$.

2.5.2. SEM. Scanning electron microscopy (SEM) was performed with a Hitachi Model S-3000H by focusing on nanoparticles to study the morphology.
2.5.3. XRD. To check phase formation and purity, XRD pattern was recorded using an X-ray diffractometer (X'per $\mathrm{PRO}$ model) using $\mathrm{CuK} \alpha$ radiation, at $40 \mathrm{keV}$ in the $2 \mathrm{~h}$ range of $10-80$.

\section{Results and Discussion}

3.1. Chemical Formula Determination of the Precursor. The chemical formula $\mathrm{M}(\mathrm{cin})_{2} \cdot\left(\mathrm{N}_{2} \mathrm{H}_{4}\right)_{2}(\mathrm{M}=\mathrm{Zn} / \mathrm{Cd})$ has been assigned to the precursor complex, based on the observed and calculated percentage values of hydrazine and the metal. The observed percentages of hydrazine (14.50) and zinc (15.00) are found to match closely with the calculated values (15.12 and 15.44) of hydrazine and zinc, respectively, proving the correctness of the determined chemical formula.

The observed percentages of hydrazine (13.70) and cadmium (23.60) are also found to match strongly with the calculated values (13.61 and 23.90) of hydrazine and cadmium, respectively, which confirms the fixed chemical formula for the corresponding precursor.

3.2. FT-IR Analysis of the Precursor. From the IR spectrum of the precursor complexes, the following are observed. The bidentate bridging nature of the hydrazine ligand in $\mathrm{Zn}(\mathrm{cin})_{2} \cdot\left(\mathrm{N}_{2} \mathrm{H}_{4}\right)_{2}$ and $\mathrm{Cd}(\mathrm{cin})_{2} \cdot\left(\mathrm{N}_{2} \mathrm{H}_{4}\right)_{2}$ is shown by the $\mathrm{N}-$ $\mathrm{N}$ stretching frequencies at $968 \mathrm{~cm}^{-1}$ and $962 \mathrm{~cm}^{-1}$, respectively [19]. The $\Delta v\left(v_{\text {asymm }}-v_{\text {sym }}\right)$ separation of carboxylate groups at $194 \mathrm{~cm}^{-1}$ and $196 \mathrm{~cm}^{-1}$ indicate their monodentate linkage in both the complexes. The $\mathrm{N}-\mathrm{H}$ stretching bands of $\mathrm{N}_{2} \mathrm{H}_{4}$ molecule appeared as a triplet in the region $3300 \mathrm{~cm}^{-1}$ in both the complexes.

3.3. Thermal Analysis of the Precursor. As can be observed from Figure $1(\mathrm{a})$, the precursor $\mathrm{Zn}(\mathrm{cin})_{2} \cdot\left(\mathrm{N}_{2} \mathrm{H}_{4}\right)_{2}$ loses weight in three particular steps. The first step is the loss of one of the hydrazine molecules between 142 and $201^{\circ} \mathrm{C}$. The corresponding peak in DTA is observed as an endotherm at $173^{\circ} \mathrm{C}$. In the second step, zinc cinnamate is formed by the loss of another hydrazine molecule, which is also endothermic and observed at $219^{\circ} \mathrm{C}$ in DTA. The major weight loss of $80 \%$ 


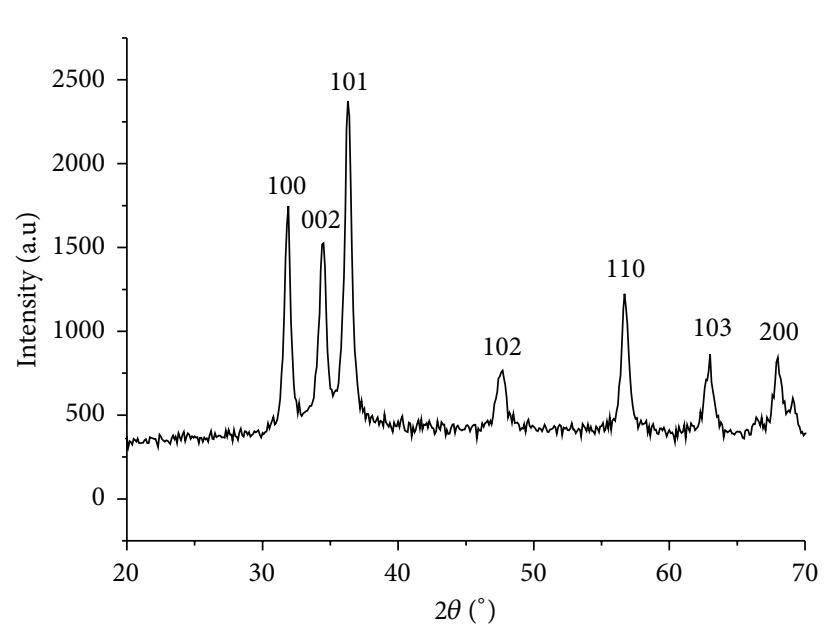

(a)

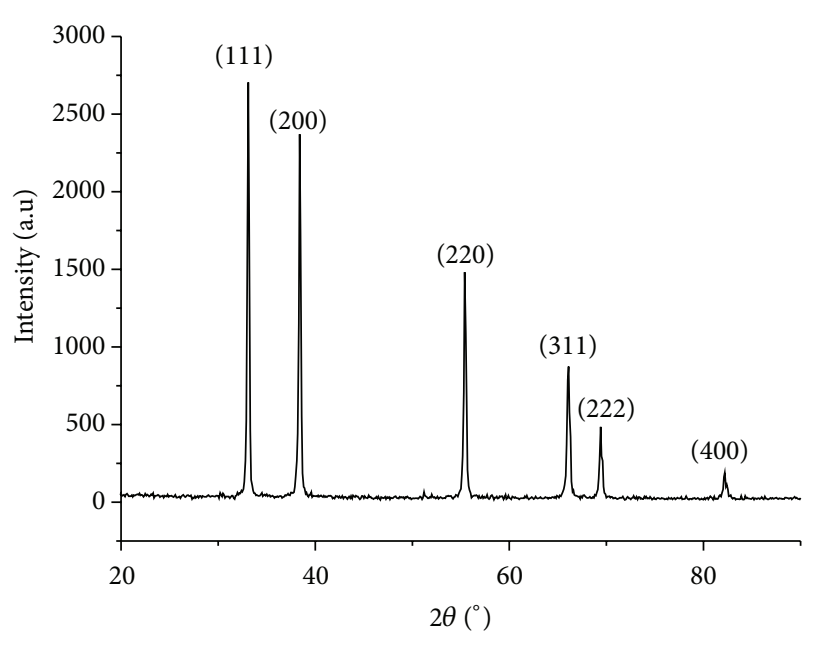

(b)

Figure 2: (a) X-ray diffraction pattern of ZnO nanoparticles, (b) X-ray diffraction pattern of CdO nanoparticles.

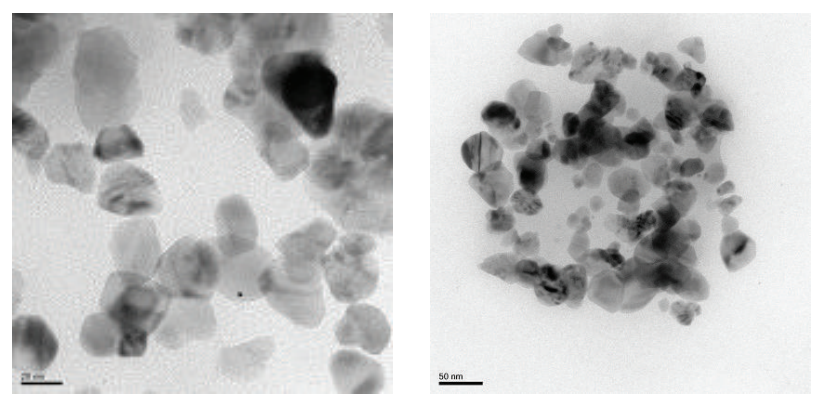

(a)
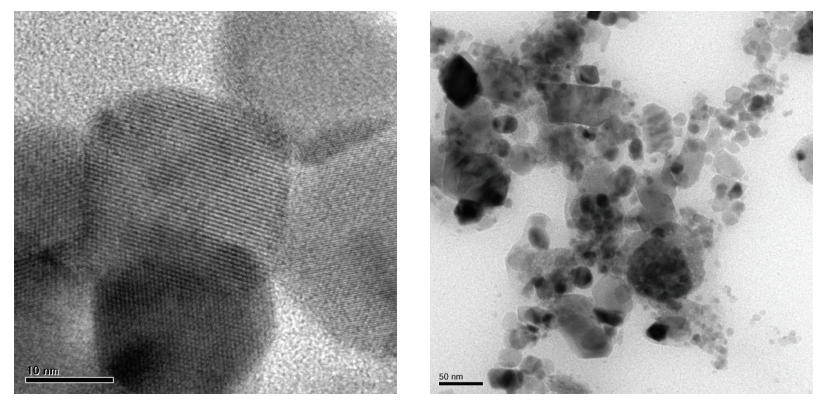

(b)

FIgURE 3: (a) TEM micrograph of $\mathrm{ZnO}$ nanoparticle, (b) TEM micrograph of $\mathrm{CdO}$ nanoparticles.

on the TG curve from 231 to $525^{\circ} \mathrm{C}$ is attributed to the third step involving the decarboxylation of the dehydrazinated precursor, which gives zinc oxide as the final residue.

From the simultaneous TG-DTA curves in Figure 1(b), the precursor $\mathrm{Cd}(\mathrm{cin})_{2} \cdot\left(\mathrm{N}_{2} \mathrm{H}_{4}\right)_{2}$ loses weight in three particular steps. The first step is the endothermic dehydrazination of the two hydrazine molecules between 166 and $297^{\circ} \mathrm{C}$. In the second step, the unstable cadmium cinnamate gives cadmium acetate as the intermediate exothermically in the temperature range, $297-395^{\circ} \mathrm{C}$. Our attempt to separate the cadmium acetate intermediate was unsuccessful since the decomposition is continuous and is proposed from the percentage weight loss which best fits with the TG curve. In the third step, the proposed intermediate undergoes exothermic decomposition to give $\mathrm{CdO}$ as the end product.

\subsection{Characterization of Zinc Oxide and Cadmium Oxide} Nanoparticles. The X-ray diffraction spectrum (Figure 2(a)) of $\mathrm{ZnO}$ nanocrystals has three similar characteristic peaks, $36.28,31.82$, and 34.40, which can, respectively, be indexed to

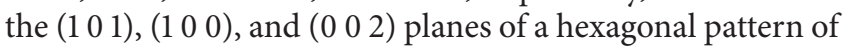
$\mathrm{ZnO}$ (JCPDS card no. 89-0510) [20] with lattice constants $a=$ $3.2488 \mathrm{~A}$ and $c=5.2054 \mathrm{~A}$. The measured $c / a$ value of 1.60 was found to match closely with the value 1.633 for an ideally close packed hexagonal structure (hcp) [21]. The strong diffraction peaks in the XRD spectrum of $\mathrm{CdO}$ (Figure 2(b)) at $2 \theta$ values of $33.04,38.33$, and 55.33 corresponding to the (1 111$)$, (2 0 0 ), and (2 20 ) planes can be indexed to a cubic pattern of CdO (JCPDS card no. 65-2908). The average particle size was calculated using Debye-Scherrer formula, $D=K \lambda / \beta \cos \theta$, where $\theta$ is Bragg diffraction angle, $K$ is Blank's constant, $\lambda$ is the source wavelength (1.54), and $\beta$ is the width of the XRD peak at half maximum height. The calculated average particle sizes of zinc oxide and cadmium oxide nanoparticles were found to be around $13 \mathrm{~nm}$ and $30 \mathrm{~nm}$, respectively. No characteristic peaks for other impurities were detected, confirming that the products obtained are phase pure.

The TEM micrograph of $\mathrm{ZnO}$ and $\mathrm{CdO}$ powders synthesised by the thermal decomposition of the precursors are pictured in Figures 3(a) and 3(b). The presence of some bigger particles should be attributed to the aggregation or overlapping of some small particles. The average particle sizes of $\mathrm{ZnO}$ and $\mathrm{CdO}$ nanoparticles observed from the micrograph are about $12-15 \mathrm{~nm}$ and $30-31 \mathrm{~nm}$, respectively, which are in agreement with the calculations using Scherrer's equation. Figures 4(a) and 4(b) show the selected area 


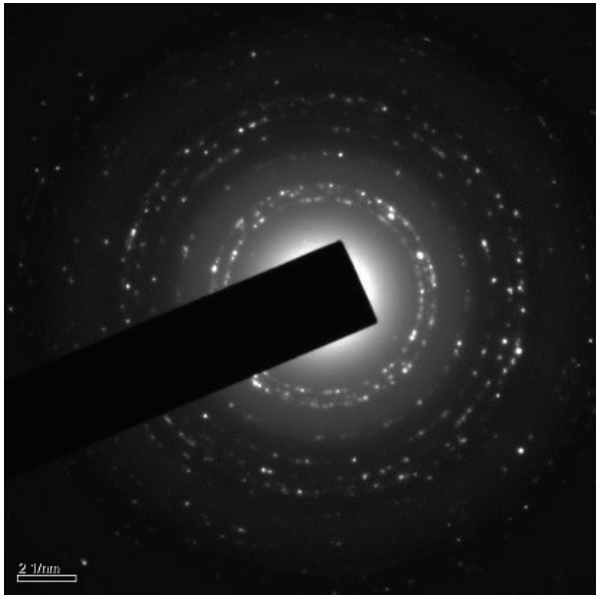

(a)

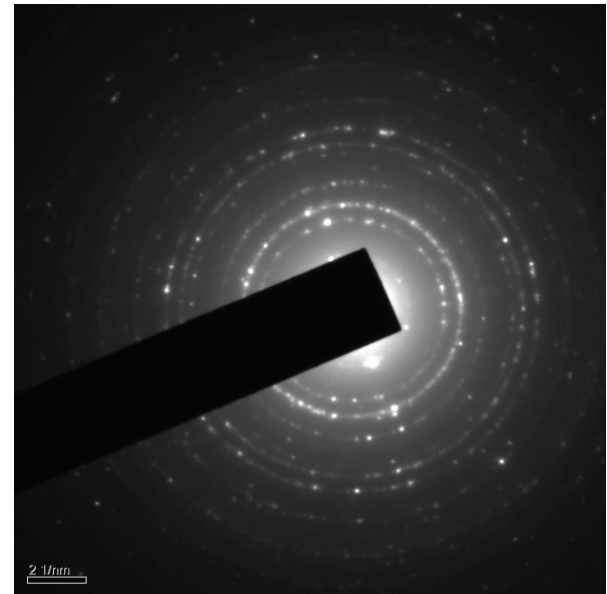

(b)

FIGURE 4: (a) SAED pattern of $\mathrm{ZnO}$ nanoparticles, (b) SAED pattern of CdO nanoparticles.

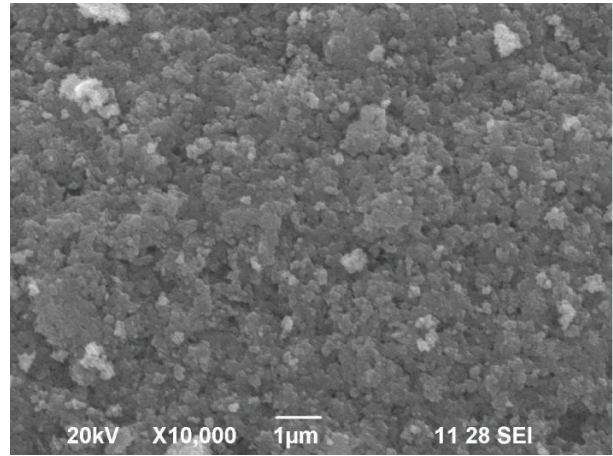

(a)

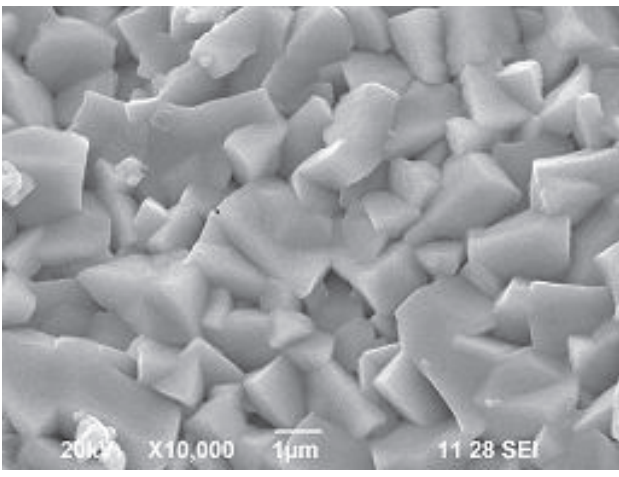

(c)

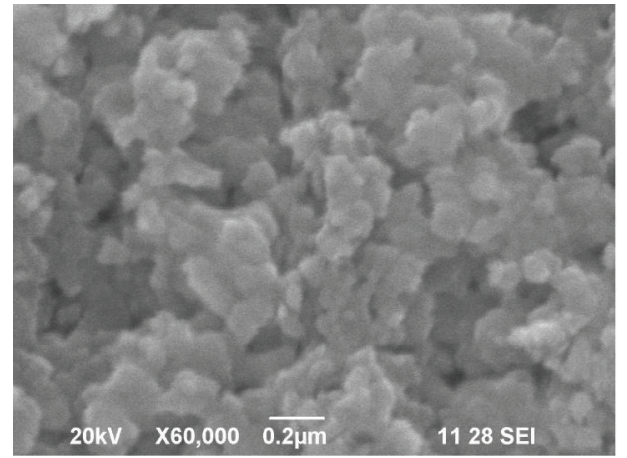

(b)

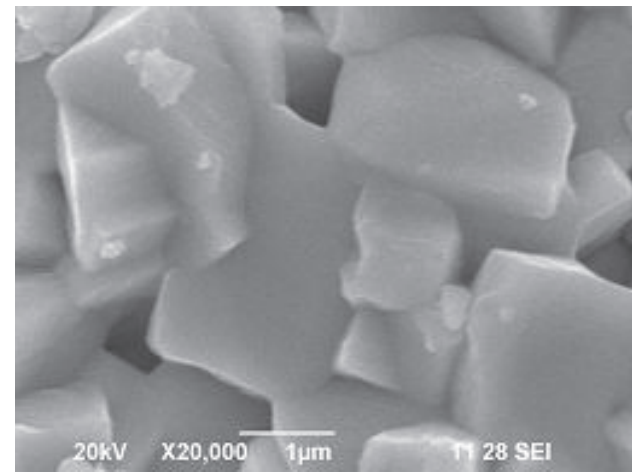

(d)

FIGURE 5: (a) SEM micrograph of ZnO nanoparticles (×10000), (b) SEM micrograph of ZnO nanoparticles $(\times 60000)$, (c) SEM micrograph of CdO nanoparticles $(\times 10000)$, (d) SEM micrograph of CdO nanoparticles $(\times 20000)$.

electron diffraction (SAED) patterns indicating sharp rings, which reveal the polycrystalline nature of the nanoparticles.

The morphologies of the as-synthesised zinc oxide and cadmium oxide nanoparticles were characterised by Scanning electron microscope (SEM). The SEM images of $\mathrm{ZnO}$ and $\mathrm{CdO}$ nanoparticles synthesised through decomposition route are shown in Figures 5(a) and 5(b). The SEM pictures clearly show randomly distributed $\mathrm{ZnO}$ grains with smaller size and rock candy like $\mathrm{CdO}$ structures with agglomeration of particles. EDX spectra of $\mathrm{ZnO}$ and $\mathrm{CdO}$ nanoparticles are presented in Figures 6(a) and 6(b), which furnish the chemical compositional analysis of the nanoscale $\mathrm{ZnO}$ and CdO.

\section{Conclusion}

$\mathrm{ZnO}$ and $\mathrm{CdO}$ nanoparticles were successfully synthesised through a simple and novel thermal decomposition method from the corresponding inorganic precursors, 


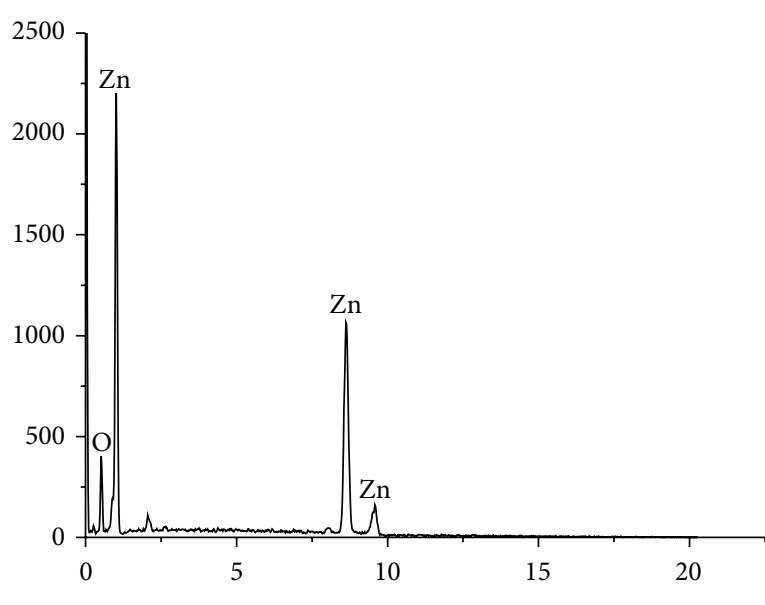

(a)

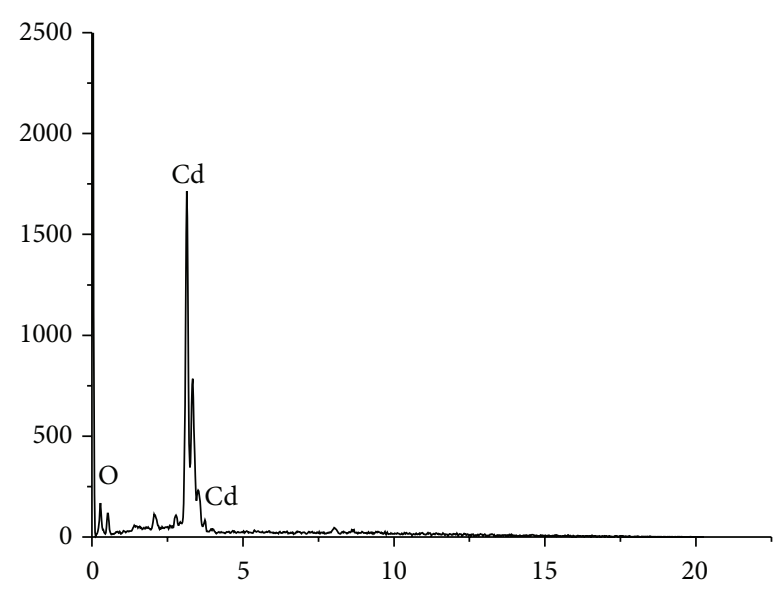

(b)

FIGURE 6: (a) EDX spectrum of $\mathrm{ZnO}$ nanoparticles, (b) EDX spectrum of CdO nanoparticles.

$\mathrm{Z}(\mathrm{cin})_{2} \cdot\left(\mathrm{N}_{2} \mathrm{H}_{4}\right)_{2}$ and $\mathrm{Cd}(\mathrm{cin})_{2} \cdot\left(\mathrm{N}_{2} \mathrm{H}_{4}\right)_{2}$, and characterised by XRD, TEM, SAED, and SEM techniques. The average particle sizes of $\mathrm{ZnO}$ and $\mathrm{CdO}$ particles determined from XRD and TEM are about $13 \mathrm{~nm}$ and $30 \mathrm{~nm}$, respectively. The present method is very simple, effective, and economically viable. It does not require the constraint of sophisticated equipment and pricey chemicals. Therefore, this method can be employed at large scale for the industrial production of metal oxide nanoparticles.

\section{References}

[1] C. Feldmann and H. O. Jungk, "Polyol-Mediated preparation of nanoscale oxide particles," Angewandte Chemie, vol. 40, no. 2, pp. 359-362, 2001.

[2] K. Holmberg, Handbook of Applied Surface and Colloid Chemistry, vol. 1-2, John Wiley, NewYork, NY, USA, 2001.

[3] W. F. Elseviers and H. Verelst, "Transition metal oxides for hot gas desulphurisation," Fuel, vol. 78, no. 5, pp. 601-612, 1999.

[4] K. M. Abd El-Salaam and E. A. Hassan, "Active surface centres in a heterogeneous $\mathrm{CdO}$ catalyst for ethanol decomposition," Surface Technology, vol. 16, no. 2, pp. 121-128, 1982.

[5] R. Mochinaga, T. Yamasaki, and T. Arakawa, "The gas-sensing of $\mathrm{SmCoO}_{x} / \mathrm{MO}_{x}(\mathrm{M}=\mathrm{Fe}, \mathrm{Zn}, \mathrm{In}, \mathrm{Sn})$ having a heterojunction," Sensors and Actuators B, vol. 52, no. 1-2, pp. 96-99, 1998.

[6] D. G. Shchukin, D. V. Sviridov, and A. I. Kulak, "Integrating photoelectrochemical semiconductor sensor for sulphide ion determination," Sensors and Actuators B, vol. 76, no. 1-3, pp. 556-559, 2001.

[7] R. S. Mane, H. M. Pathan, C. D. Lokhande, and S.-H. Han, "An effective use of nanocrystalline $\mathrm{CdO}$ thin films in dye-sensitized solar cells," Solar Energy, vol. 80, no. 2, pp. 185-190, 2006.

[8] D. Gal, G. Hodes, D. Lincot, and H.-W. Schock, "Electrochemical deposition of zinc oxide films from non-aqueous solution: a new buffer/window process for thin film solar cells," Thin Solid Films, vol. 361, pp. 79-83, 2000.

[9] R. Kaur, A. V. Singh, and R. M. Mehra, "Sol-gel derived highly transparent and conducting yttrium doped $\mathrm{ZnO}$ films," Journal of Non-Crystalline Solids, vol. 352, no. 23-25, pp. 2335-2338, 2006.
[10] J. Zhang, H. Feng, W. Hao, and T. Wang, "Blue-emitting ZnO sol and film obtained by sol-gel process," Journal of Sol-Gel Science and Technology, vol. 39, no. 1, pp. 37-39, 2006.

[11] W. Dong and C. Zhu, "Optical properties of surface-modified CdO nanoparticles," Optical Materials, vol. 22, pp. 227-233, 2003.

[12] D. Sarkar, S. Tikku, V. Thapar, R. S. Srinivasa, and K. C. Khilar, "Formation of zinc oxide nanoparticles of different shapes in water-in-oil microemulsion," Colloids and Surfaces A, vol. 381, no. 1-3, pp. 123-129, 2011.

[13] M. Ristic, S. Popovic, and S. Music, "Formation and properties of $\mathrm{Cd}(\mathrm{OH})_{2}$ and CdO particles," Materials Letters, vol. 58, pp. 2494-2499, 2004.

[14] F. Zhang, F.-L. Bei, J.-M. Cao, and X. Wang, "The preparation of CdO nanowires from solid-state transformation of a layered metal-organic framework," Journal of Solid State Chemistry, vol. 181, no. 1, pp. 143-149, 2008.

[15] Y. Wang and M. Li, "Hydrothermal synthesis of singlecrystalline hexagonal prism $\mathrm{ZnO}$ nanorods," Materials Letters, vol. 60, pp. 266-269, 2006.

[16] R. B. Waghulade, P. P. Patil, and R. Pasricha, "Synthesis and LPG sensing properties of nano-sized cadmium oxide," Talanta, vol. 72, no. 2, pp. 594-599, 2007.

[17] H. B. Lu, L. Liao, H. Li et al., "Fabrication of CdO nanotubes via simple thermal evaporation," Materials Letters, vol. 62, no. 24, pp. 3928-3930, 2008.

[18] I. Vogel, A Textbook of Quantitative Inorganic Analysis, Longman, UK, 4th edition, 1985.

[19] A. Braibanti, F. Dallavalle, M. A. Pellinghelli, and E. Leporati, "The nitrogen-nitrogen stretching band in hydrazine derivatives and complexes," Inorganic Chemistry, vol. 7, no. 7, pp. 14301433, 1968

[20] H. Sawada, R. Wang, and A. W. Sleight, "An electron density residual study of zinc oxide," Journal of Solid State Chemistry, vol. 122, no. 1, pp. 148-150, 1996.

[21] N. L. Tarwal, P. R. Jadhav, S. A. Vanalakar et al., "Photoluminescence of zinc oxide nanopowder synthesized by a combustion method," Powder Technology, vol. 208, no. 1, pp. 185-188, 2011. 

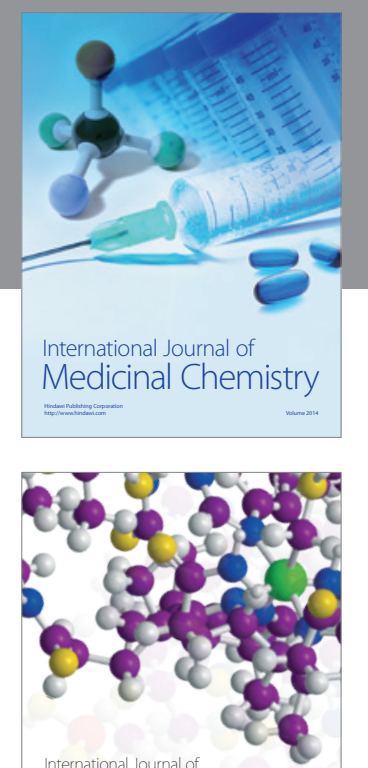

\section{Carbohydrate} Chemistry

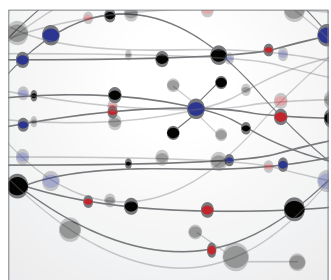

The Scientific World Journal
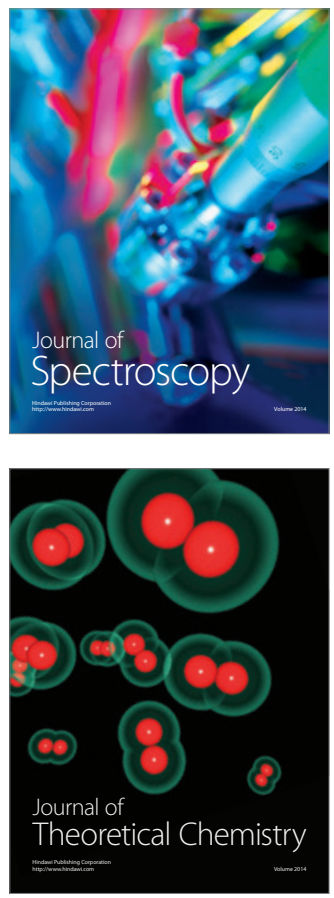
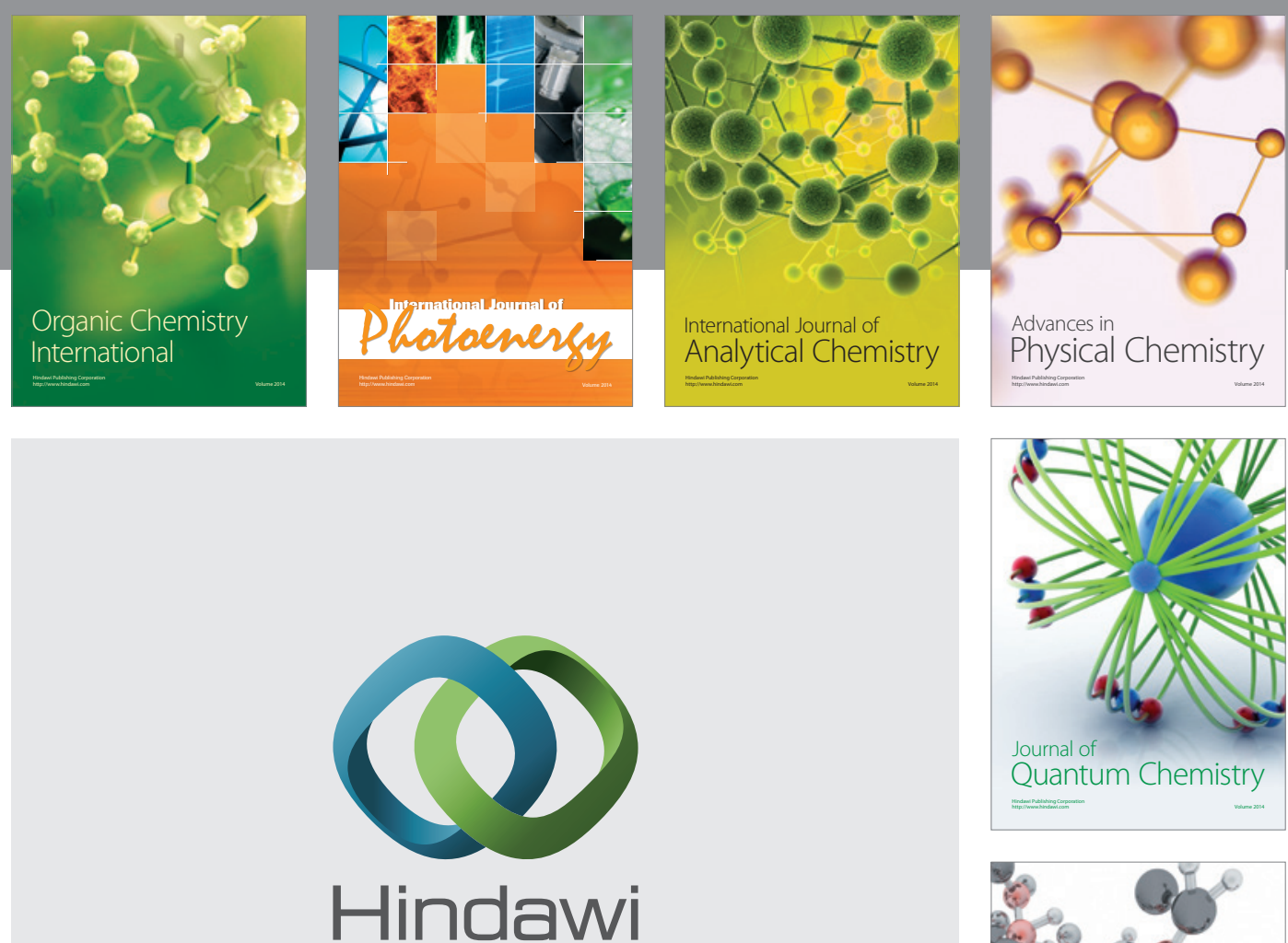

Submit your manuscripts at

http://www.hindawi.com

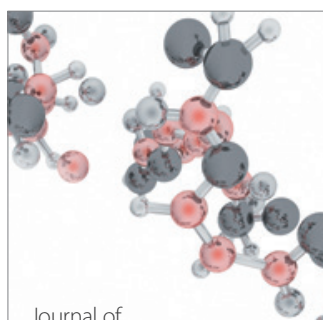

Analytical Methods

in Chemistry

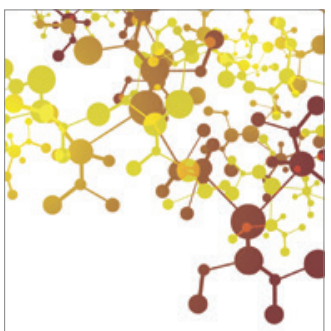

Journal of

Applied Chemistry

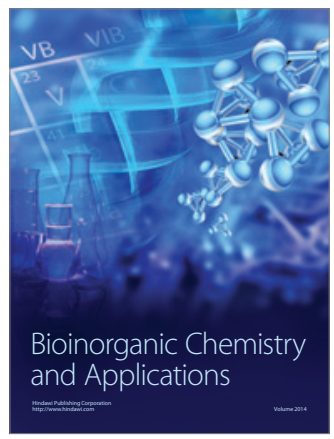

Inorganic Chemistry
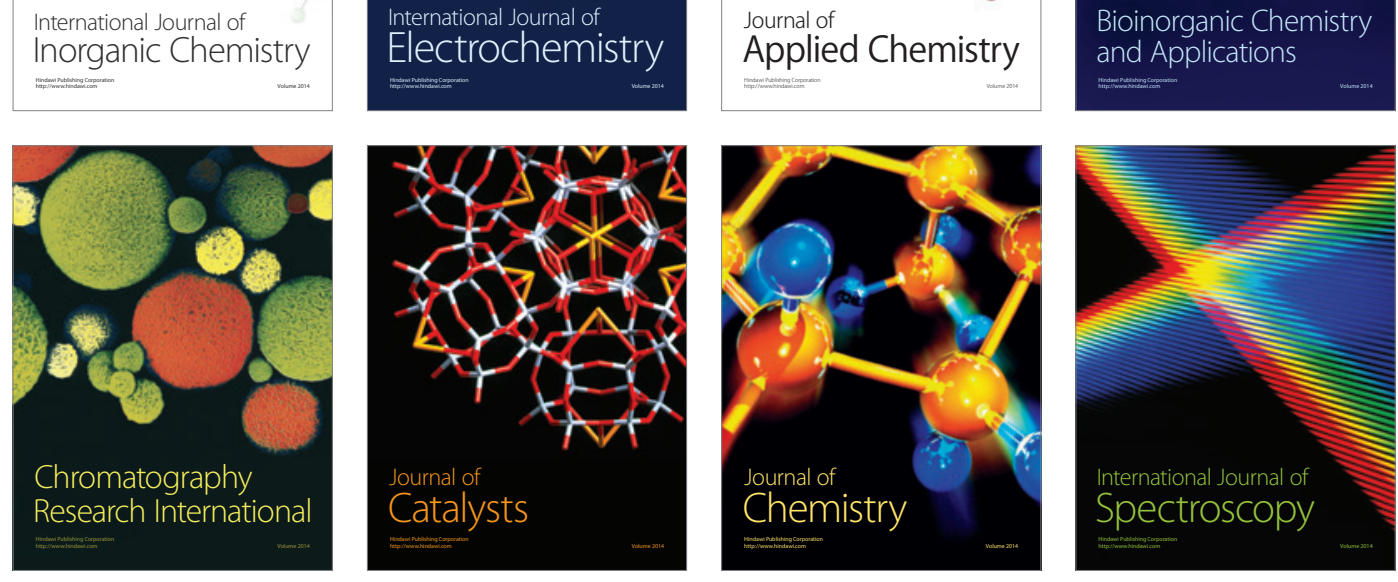